\title{
A novel photoresponsive benzoquinolone: evaluation of the release of model amino acids
}

\author{
Ana M. S. Soares, Andrêa S. C. Fonseca, Susana P. G. Costa, M. Sameiro T. Gonçalves \\ Centro de Química, Universidade do Minho, Campus de Gualtar, 4710-057 Braga, Portugal \\ spc@quimica.uminho.pt
}

\begin{abstract}
A photoresponsive benzoquinolone was conjugated with two model amino acids at their $C$-terminus, affording the corresponding ester conjugates. These ester conjugates were submitted to photocleavage studies in different mixtures of methanol/HEPES buffer solution at different wavelengths of irradiation (300, 350 and $419 \mathrm{~nm}$ ), which confirmed the quantitative release of the model molecules in short irradiation times.
\end{abstract}

Keywords: Quinolones, photocleavage, amino acids, photolabile protecting groups.

\section{Introduction}

Photoresponsive moieties have proven useful in biochemical and biophysical studies with biomolecules that require spatial and temporal resolution of light-controlled processes. In order to develop more efficient photoactive units, with fast and clean cleavage, it is desirable that their absorption is shifted towards longer wavelengths (> $400 \mathrm{~nm}$ ), which can be accomplished by substituent tailoring at the photoactive unit or by careful choice of the solvent for the photolytic process. Shifting absorption to higher wavelength also minimises side reactions due to competing absorption of radiation by other chromophores in the molecule under study. ${ }^{1}$

Quinolone derivatives were recently reported for the first time by us for the protection of carboxylic acids, in the form of ester conjugates, by using an amino acid as model biomolecule. ${ }^{2}$ This nitrogen heterocycle, structurally related to coumarin, a well-known photocleavable protecting group ${ }^{3-5}$ assured fast cleavage of the ester bond between the amino acid and the heterocycle. Considering our current research interests which includes the design of new oxygen and nitrogen heterocycles, as well as polycyclic aromatics, and their application as photocleavable protecting groups for the amino and carboxylic functions, ${ }^{2,6-10}$ we now report our efforts to further optimize the photolytic process at longer wavelengths by using a polycyclic nitrogen heterocycle in an attempt to accomplish larger shifts of the maximum wavelength of absorption in the UV/Vis, that can influence the outcome of the 
photocleavage reaction. In this work, a novel benzoquinolone was used as photolabile protecting group of two model amino acids, alanine and glutamic acid.

The stability to irradiation of the ester bond between model amino acids and the novel benzoquinolone was evaluated in a photochemical reactor at 300, 350 and $419 \mathrm{~nm}$ using different mixtures of methanol/HEPES buffer solutions. The photolysis at different wavelengths was monitored by HPLCUV detection and kinetic data was obtained.

\section{Experimental}

\subsection{Synthesis of $N$-benzyloxycarbonyl-L-alanine (9-methoxy-4-methylbenzo[f]quinolin-3(4H)-} one-1-yl) methyl ester, $3 a$

Compound $2(0.025 \mathrm{~g}, 0.09 \mathrm{mmol})$ was dissolved in dry $N, N$-dimethylformamide $(3 \mathrm{~mL}) . N$ benzyloxycarbonyl-L-alanine 1a (1 equiv, $0.020 \mathrm{~g}, 0.09 \mathrm{mmol}$ ) and potassium fluoride (3 equiv, $0.016 \mathrm{~g}, 0.27 \mathrm{mmol}$ ) were added to the mixture. The reaction mixture was stirred at room temperature for 2 days. The mixture was filtered and the solvent was removed by rotary evaporation. The obtained crude solid was purified by silica gel column chromatography using dichloromethane/methanol (100:1) as eluent, yielding compound 3a as a brown solid $(0.015 \mathrm{~g}, 0.03 \mathrm{mmol}, 35 \%)$. Mp = 157.5$158.5^{\circ} \mathrm{C} .{ }^{1} \mathrm{H} \mathrm{NMR}\left(400 \mathrm{MHz}, \mathrm{CDCl}_{3}\right): \delta=1.47\left(3 \mathrm{H}, \mathrm{d}, J=7.2 \mathrm{~Hz}, \mathrm{CH}_{3}\right), 3.85\left(3 \mathrm{H}, \mathrm{s}, \mathrm{NCH}_{3}\right), 3.95$ $\left(3 \mathrm{H}, \mathrm{s}, \mathrm{OCH}_{3}\right), 4.50-4.54(1 \mathrm{H}, \mathrm{m}, \alpha-\mathrm{CH}), 5.08-5.15\left(2 \mathrm{H}, \mathrm{m}, \mathrm{CH}_{2} \mathrm{Z}\right), 5.39(1 \mathrm{H}, \mathrm{d}, J=7.6 \mathrm{~Hz}, \mathrm{NH})$, 5.66-5.78 (2H, m, $\left.\mathrm{CH}_{2}\right), 6.98(1 \mathrm{H}, \mathrm{s}, \mathrm{H}-2), 7.19(1 \mathrm{H}, \mathrm{dd}, J=2.4$ and $11.2 \mathrm{~Hz}, \mathrm{H}-8), 7.31-7.35(5 \mathrm{H}$, m, $5 \times \mathrm{Ph}-H \mathrm{Z}), 7.45$ (1H, d, $J=9.2 \mathrm{~Hz}, \mathrm{H}-5), 7.48(1 \mathrm{H}, \mathrm{s}, \mathrm{H}-10), 7.82(1 \mathrm{H}, \mathrm{d}, J=8.8 \mathrm{~Hz}, \mathrm{H}-7), 7.93$ $(1 \mathrm{H}, \mathrm{d}, J=9.2 \mathrm{~Hz}, \mathrm{H}-6)$ ppm. ${ }^{13} \mathrm{C} \mathrm{NMR}\left(100.6 \mathrm{MHz}, \mathrm{CDCl}_{3}\right): \delta=18.37\left(\mathrm{CH}_{3}\right), 30.60\left(\mathrm{NCH}_{3}\right), 49.78$ $(\alpha-\mathrm{C}), 55.45\left(\mathrm{OCH}_{3}\right), 65.93\left(\mathrm{CH}_{2}\right), 67.03\left(\mathrm{CH}_{2} \mathrm{Z}\right), 1006.07(\mathrm{C}-10), 112.68(\mathrm{C}-5), 113.87(\mathrm{C}-10 \mathrm{~b})$ 116.20 (C-8), 120.11 (C-2), 125.01 (C-6a), 128.10 (Ar-C), 128.14 (Ar-C), 128.47 (Ar-C), 130.77 (C7), 131.15 (C-10a), 132.42 (C-6), 136.13 (Ar-C), 141.06 (C-4a), 144.04 (C-1), 155.02 (C=O urethane), 159.35 (C-9), 161.39 (C-3), 172.50 (C=O ester) ppm.

\subsection{Synthesis of $\quad N$-benzyloxycarbonyl-5-methoxy-5-oxopentanoate (9-methoxy-4- methylbenzo[f]quinolin-3(4H)-one-1-yl) methyl ester, $3 b$}

Compound 2 (0.025 g, $0.09 \mathrm{mmol})$ was dissolved in dry $N, N$-dimethylformamide $(3 \mathrm{~mL}) . N$ benzyloxycarbonyl-L-glutamic acid methyl ester $\mathbf{1 b}$ (1 equiv, $0.027 \mathrm{~g}, 0.09 \mathrm{mmol}$ ) and potassium fluoride ( 3 equiv, $0.016 \mathrm{~g}, 0.27 \mathrm{mmol}$ ) were added to the mixture. The reaction mixture was stirred at room temperature for 2 days. The mixture was filtered and the solvent was removed by rotary evaporation. The obtained crude solid was purified by silica gel column chromatography using 
dichloromethane/methanol (100:1) as eluent, yielding compound $\mathbf{3 b}$ as a brown solid (0.006 g, 0.01 mmol, $13 \%) . \mathrm{Mp}=162.4-163.7^{\circ} \mathrm{C} .{ }^{1} \mathrm{H} \mathrm{NMR}\left(400 \mathrm{MHz}, \mathrm{CDCl}_{3}\right): \delta=2.00-2.09\left(2 \mathrm{H}, \mathrm{m}, \beta-\mathrm{CH}_{2}\right), 2.38$ $2.49\left(2 \mathrm{H}, \mathrm{m}, \gamma-\mathrm{CH}_{2}\right), 3.64\left(3 \mathrm{H}, \mathrm{s}, \mathrm{OCH}_{3}\right), 3.87\left(3 \mathrm{H}, \mathrm{s}, \mathrm{NCH}_{3}\right), 3.96\left(3 \mathrm{H}, \mathrm{s}, \mathrm{OCH}_{3}\right), 4.52-4.57(1 \mathrm{H}, \mathrm{m}$, $\alpha-\mathrm{CH}), 5.08-5.15\left(2 \mathrm{H}, \mathrm{m}, \mathrm{CH}_{2} \mathrm{Z}\right), 5.50(1 \mathrm{H}, \mathrm{d}, J=7.6 \mathrm{~Hz}, \mathrm{NH}), 5.75\left(2 \mathrm{H}, \mathrm{s}, \mathrm{CH}_{2}\right), 7.00(1 \mathrm{H}, \mathrm{s}, \mathrm{H}-2)$, $7.20(1 \mathrm{H}, \mathrm{dd}, J=2.4$ and $8.8 \mathrm{~Hz}, \mathrm{H}-8), 7.31-7.34(5 \mathrm{H}, \mathrm{m}, 5 \times \mathrm{Ph}-H \mathrm{Z}), 7.47(1 \mathrm{H}, \mathrm{d}, J=9.2 \mathrm{~Hz}, \mathrm{H}-$ 5), 7.50 (1H, s, H-10), $7.83(1 \mathrm{H}, \mathrm{d}, J=8.8 \mathrm{~Hz}, \mathrm{H}-7), 7.94(1 \mathrm{H}, \mathrm{d}, J=9.2 \mathrm{~Hz}, \mathrm{H}-6) \mathrm{ppm} .{ }^{13} \mathrm{C}$ NMR $\left(100.6 \mathrm{MHz}, \mathrm{CDCl}_{3}\right): \delta=27.25\left(\beta-\mathrm{CH}_{2}\right), 29.93\left(\gamma-\mathrm{CH}_{2}\right), 30.64\left(\mathrm{NCH}_{3}\right), 51.85\left(\mathrm{OCH}_{3}\right), 53.63(\alpha-\mathrm{C})$, $55.47\left(\mathrm{OCH}_{3}\right), 66.19\left(\mathrm{CH}_{2}\right), 67.18\left(\mathrm{CH}_{2} \mathrm{Z}\right), 106.05(\mathrm{C}-10), 112.69(\mathrm{C}-5), 113.91(\mathrm{C}-10 \mathrm{~b}) 116.25(\mathrm{C}-$ 8), 120.41 (C-2), 125.03 (C-6a), 128.13 (Ar-C), 128.19 (Ar-C), 128.50 (Ar-C), 130.79 (C-7), 131.17 (C-10a), 132.47 (C-6), 136.06 (Ar-C), 141.12 (C-4a), 143.84 (C-1), 155.95 (C=O urethane), 159.40 (C-9), 161.38 (C-3), 171.46 (C=O ester), 173.00 (C=O ester) ppm.

\subsection{General photolysis procedure}

A $1 \times 10^{-4} \mathrm{M}$ methanol/HEPES buffer (80:20 and 60:40) solutions of conjugates 3a,b (5 mL) was placed in a quartz tube and irradiated in a Rayonet RPR-100 reactor at the desired wavelength. The lamps used for irradiation were of 300, 350 and 419 $\pm 10 \mathrm{~nm}$. HEPES buffer solution was prepared in distilled water with HEPES (4-(2-hydroxyethyl)-1-piperazine ethanesulfonic acid) (10 mM), $\mathrm{NaCl}$ (120 mM), $\mathrm{KCl}(3 \mathrm{mM}), \mathrm{CaCl}_{2}(1 \mathrm{mM})$ and $\mathrm{MgCl}_{2}(1 \mathrm{mM})$ and $\mathrm{pH}$ adjusted to 7.2. Aliquots of 100 $\mu \mathrm{L}$ were taken at regular intervals and analysed by RP-HPLC. The eluent was acetonitrile/water (3:1) at a flow rate of $0.8 \mathrm{~mL} / \mathrm{min}$ for all compounds, previously filtered through a Millipore, type HN 0.45 $\mu \mathrm{m}$ filter and degassed by ultra-sound for $30 \mathrm{~min}$. The chromatograms were traced by detecting UV absorption at the wavelength of maximum absorption (retention time: $5.5 \mathrm{~min}, \mathbf{3 a}$; $5.1 \mathrm{~min}, \mathbf{3 b}$ ).

\section{Results and Discussion}

1-Chloromethyl-9-methoxy-4-methylbenzo[f]quinolin-3(4H)-one 2 (previously synthesized by us) ${ }^{11}$ was used in the preparation of ester conjugates $\mathbf{3 a}, \mathbf{b}$, by reaction with $N$-benzyloxycarbonyl-L-alanine 1a and $N$-benzyloxycarbonyl-L-glutamic acid methyl ester $\mathbf{1 b}$, as model amino acids, in $N, N$ dimethylformamide, at room temperature, in the presence of potassium fluoride (Scheme 1). The new conjugates were characterized by ${ }^{1} \mathrm{H}$ and ${ }^{13} \mathrm{C}$ NMR spectroscopy. 


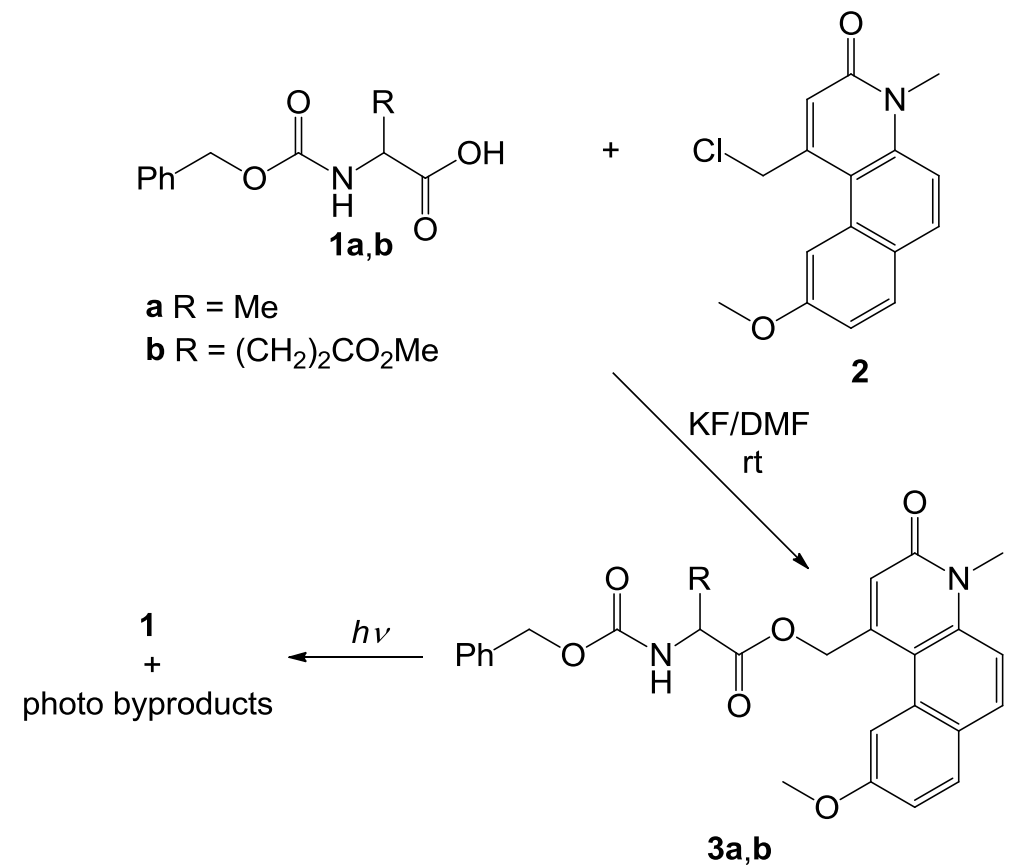

Scheme 1. Synthesis and photolysis of conjugates $\mathbf{3 a}, \mathbf{b}$.

The photophysical properties of the new ester conjugates $\mathbf{3 a} \mathbf{a}, \mathbf{b}$ were evaluated by tracing the UV/Vis absorption and emission spectra of degassed $10^{-5} \mathrm{M}$ solutions in ethanol, methanol/HEPES buffer (80:20) solution and methanol/HEPES buffer (60:40) solution. Relative fluorescence quantum yields were calculated using 9,10-diphenylanthracene as standart $\left(\phi_{\mathrm{F}}=0.95\right.$ in ethanol). ${ }^{12} \mathrm{UV} / \mathrm{Vis}$ absorption and emission characterization was also carried out to obtain the parameters needed for monitoring during photolysis (Table 1).

Table 1. UV/Vis absorption and fluorescence data for compounds $\mathbf{3 a}$ and $\mathbf{3 b}$ in ethanol, methanol/HEPES buffer (80:20) and methanol/HEPES buffer (60:40) solutions.

\begin{tabular}{ccccccc}
\hline Compound & Solvent & $\lambda_{\mathrm{abs}}(\mathrm{nm})$ & $\log \varepsilon$ & $\lambda_{\mathrm{em}}(\mathrm{nm})$ & $\Phi_{\mathrm{F}}$ & $\Delta \lambda(\mathrm{nm})$ \\
\hline 3a & 340 & 3.42 & 417 & 0.19 & 77 \\
& $\begin{array}{c}\text { Ethanol } \\
\text { MeOH/HEPES } \\
(80: 20)\end{array}$ & 340 & 3.40 & 410 & 0.17 & 70 \\
& $\begin{array}{c}\text { MeOH/HEPES } \\
(60: 40)\end{array}$ & 340 & 3.89 & 417 & 0.14 & 77 \\
& $\begin{array}{l}\text { Ethanol } \\
\text { 3b }\end{array}$ & 340 & 3.49 & 417 & 0.18 & 77 \\
& $\begin{array}{c}\text { MeOH/HEPES } \\
(80: 20)\end{array}$ & 340 & 3.80 & 418 & 0.16 & 78 \\
MeOH/HEPES & 340 & 3.50 & 417 & 0.15 & 77 \\
\hline
\end{tabular}


By comparison of the data presented on Table 1, it could be observed that the nature of the amino acid did not influence the photophysical properties of the resulting conjugate. The same observation was made in terms of fluorescence quantum yields, as the increase of the aqueous HEPES content in the solvent did not alter the quantum yields. In both solvents, the Stokes' shift $(\Delta \lambda)$ was between 70 and $78 \mathrm{~nm}$, which is an advantageous property when using fluorescence techniques, as it will minimize self-quenching phenomena.

The release of model amino acids from conjugates 3a,b was carried out by photolysis at different wavelengths. Solutions of the mentioned compounds $\left(1 \times 10^{-4} \mathrm{M}\right)$ in methanol/HEPES buffer (80:20) solution and methanol/HEPES buffer (60:40) solution, were irradiated in a Rayonet RPR-100 reactor at 300, 350 and $419 \mathrm{~nm}$, in order to determine the most favorable cleavage conditions. The behavior towards irradiation of mentioned conjugates was followed by reverse phase HPLC with UV detection. The determined irradiation time represents the time necessary for the consumption of the starting materials until less than $5 \%$ of the initial area was detected (Table 2).

Table 2. Irradiation times ( $\mathrm{t}_{i r}$, in $\left.\mathrm{min}\right)$ and $k\left(10^{-2} \mathrm{~min}^{-1}\right)$ for the complete photolysis $(95 \%)$ of compounds $\mathbf{3 a}$ and $\mathbf{3 b}$ at different wavelengths and in different solvents: A - methanol/HEPES (80:20); B - methanol/HEPES (60:40).

\begin{tabular}{|c|c|c|c|c|c|c|c|}
\hline \multirow{2}{*}{ Compound } & \multirow{2}{*}{ Solvent } & \multicolumn{2}{|c|}{$300 \mathrm{~nm}$} & \multicolumn{2}{|c|}{$350 \mathrm{~nm}$} & \multicolumn{2}{|c|}{$419 \mathrm{~nm}$} \\
\hline & & $t_{\text {irr }}$ & $k$ & $t_{\text {irr }}$ & $k$ & $t_{\text {irr }}$ & $k$ \\
\hline \multirow{2}{*}{$3 \mathbf{a}$} & $\mathbf{A}$ & 9.6 & 31.3 & 10.4 & 28.9 & 1181 & 15.0 \\
\hline & B & 9.1 & 33.1 & 8.2 & 36.4 & 505 & 35.5 \\
\hline \multirow{2}{*}{$3 b$} & $\mathbf{A}$ & 14.8 & 20.1 & 11.5 & 26.2 & 1038 & 17.5 \\
\hline & B & 7.2 & 40.5 & 7.0 & 42.6 & 436 & 41.4 \\
\hline
\end{tabular}

Considering the results in Table 2, it was found that higher water content had a positive influence in the cleavage rates, resulting in shorter irradiation times. Such behaviour might be explained by the nature of the photocleavage mechanism that could resemble that of the coumarin system, involving an ionic pair formed by homolytical (followed by electron transfer) or heterolytical cleavage of the ester $\mathrm{O}-\mathrm{CH}_{2}$ bond. ${ }^{13}$

Fast cleavage was possible by irradiation at 300 and $350 \mathrm{~nm}$ whereas at $419 \mathrm{~nm}$ the irradiation times were too long to be useful for practical applications. 


\section{Conclusions}

The synthesis of ester conjugates using a novel nitrogen heterocycle, a benzoquinolone derivative, was described. This novel benzoquinolone proved to be useful for application as photocleavable protecting group, with very short irradiation times at 300 and $350 \mathrm{~min}$ (between 7 and $15 \mathrm{~min}$ ) being necessary for the complete release of the model amino acids. The best results obtained show that the amount of water in the solvent mixture influences the photolysis rates, cleaving faster in higher water content.

\section{Acknowledgements}

We thank the Fundação para a Ciência e Tecnologia (FCT) for financial support to the NMR portuguese network (PTNMR, Bruker Avance III 400-Univ. Minho), FCT and FEDER-COMPETEQREN-EU for financial support to the Research Centre CQ/UM [PEst-C/QUI/UI0686/2013 (FCOMP-01-0124-FEDER-037302)], and a PhD grant to A.M.S.S. (SFRH/BD/80813/2011).

\section{References}

1) P. Klan, T. Solomek, C. G. Bochet, A. Blanc, R. Givens, M. Rubina, V. Popik, A. Kostikov, J. Wirz, Chem. Rev., 2013, 113, 119-191.

2) A. S. C. Fonseca, M. S. T. Gonçalves, A. P. G. Costa, Amino Acids, 2010, 39, 699-712.

3) V. Hagen, F. Kilic, J. Schaal, B. Dekowski, R. Schmidt, N. Kotzu, J. Org. Chem., 2010, 75, 27902797.

4) A. M. Piloto, A. M. S. Soares, G. Hungerford, S. P. G. Costa, M. S. T. Gonçalves, Eur. J. Org. Chem., 2011, 5447-5451.

5) A. M. S. Soares, S. P. G. Costa, M. S. T. Gonçalves, Amino Acids, 2010, 39, 121-133.

6) M. J. G. Fernandes, S. P. G. Costa, M. S. T. Gonçalves, Tethrahedron, 2011, 67, 2422-2426.

7) A. S. C. Fonseca, M. S. T. Gonçalves, S. P. G. Costa, Tethrahedron, 2012, 68, 8024-8032.

8) A. M. S. Soares, A. M. Piloto, G. Hungerford, S. P. G. Costa, M. S. T. Gonçalves, Eur. J. Org. Chem., 2012, 922-930.

9) A. M. Piloto, G. Hungerford, S. P. G. Costa, M. S. T. Gonçalves, Photochem. Photobiol. Sci., 2013, 12, 339-347.

10) A. S. C. Fonseca, M. S. T. Gonçalves, S. P. G. Costa, Amino Acids, 2012, 43, 2329-2338.

11) A. S. C. Fonseca, A. M. S. Soares, M. S. T. Gonçalves, S. P. G. Costa, Photochem. Photobiol. Sci., submitted. 
12) J. V. Morris, M. A. Mahaney, J. R. Huber, J. Phys. Chem., 1976, 80, 969-974.

13) M. Yamaji, K. Nozali, X. Allonas, S. Nakajima, S. Tero-Kubota, B. Marciniak, J. Phys. Chem. A, 2009, 113, 5815-5822. 